\title{
Characterization of the Attended Surgical Patients in the Assisted Reproduction Territorial Centre, Cienfuegos 2015-2016
}

\author{
Felix Arístides Somarriba Aráuz, Práxedes de Regla Rojas Quintana (1), \\ Santiago Bernia Sarría, María Elizabeth Ixcoy García, Aimé Reyes Pérez ${ }^{\circledR}$, \\ Armando Bernia González
}

Gustavo Aldereguía Lima General University Hospital, Cienfuegos, Cuba

Email: praxedes.rojas@gal.sld.cu, preglarojas96@gmail.com, santiago.bernia@gal.sld.cu, aime.reyes@gal.sld.cu

How to cite this paper: Aráuz, F.A.S., de Regla Rojas Quintana, P., Sarría, S.B., García, M.E.I., Pérez, A.R. and González, A.B. (2020) Characterization of the Attended Surgical Patients in the Assisted Reproduction Territorial Centre, Cienfuegos 2015-2016. Modern Research in Inflammation, 9, 19-31.

https://doi.org/10.4236/mri.2020.93003

Received: June 28, 2020

Accepted: August 27, 2020

Published: August 30, 2020

Copyright $\odot 2020$ by author(s) and Scientific Research Publishing Inc. This work is licensed under the Creative Commons Attribution International License (CC BY 4.0).

http://creativecommons.org/licenses/by/4.0/

\begin{abstract}
Introduction: Infertility is a health problem that does not cause death, disability or physical pain; however, it is a crisis for couples who see their life plans threatened and suffer not only at the time of diagnosis and during treatments, but in multiple daily situations. Scientific Problem: There are no published studies on the characteristics of the infertile patient who has required surgical treatment, which is attended at the Territorial Center for Assisted Reproduction, Cienfuegos. Objective: To characterize the patients with infertility diagnosis who underwent surgical treatment and were treated at the Territorial Center for the care of the infertile couple in the province of Cienfuegos. Methodological Design: A descriptive, prospective, cross-sectional study of a series of cases was carried out at the Territorial Center for Assisted Reproduction, inserted in the Department of External Consultation of the General University Hospital, Dr. "Gustavo Aldereguía Lima” in Cienfuegos, in the period from January 2015 to December 2016. The variables studied were: age, skin color, pelvic inflammatory disease, personal pathological history, number of pregnancies, number of deliveries, number of abortions, age of the first sexual relations, cause of infertility, time attending the consultation, previous pelvic surgery, preoperative diagnosis, type of surgery, type of treatment and results of the surgery. Results: A predominance of age was obtained between 26 and 35 years of previous pelvic inflammatory disease, Bronchial Asthma as a personal pathological antecedent, previous pelvic surgery, number of pregnancies between 1 and 2 , induced abortion among other results.
\end{abstract}

\section{Keywords}

Infertility, Pelvic Inflammatory Disease, Pregnancies, Abortion, Surgery 


\section{Introduction}

Infertility is a health problem that does not cause death, disability, or physical pain; however, it is a crisis for couples, who see their life plans threatened and suffer not only at the time of diagnosis and during treatments, but in multiple everyday situations. The cult of fertility is something as old as human existence is and has been of great importance to its survival. Infertility has come to be considered in many different ways: as dishonor, as inferiority, as a curse or punishment from the gods, and even in Egypt, it was considered as a cause for the dissolution of marriage [1].

Human reproductive efficiency is low in relation to that of most other animal species, and the maximum peak of human fertility (understanding as such the chances of pregnancy per menstrual cycle in the most fertile couples) is not higher than $30 \%-35 \%$ [2].

Infertility, defined by the biomedical system as the inability of a couple to achieve a pregnancy in a 12-month period of sexual activity without the use of contraceptive methods, rather than a medical problem, is a social problem of reproductive health [3].

The most frequent causes of infertility in women are: tubal obstructions, polycystic ovary syndrome, anovulation, hyperprolactinemia, cervical stenosis, uterine fibromatosis, endometriosis, malformations in the genital tract, etc. and others that may not be identified [4].

Alterations in normal tubal anatomy and function correspond to $40 \%$ of female infertility. Pelvic inflammatory disease (PID) is the most common cause of infertility. Appendicitis, pelvic surgery, and less frequently endometriosis, also appear as causes of distal tubal occlusion, along with varying degrees of dilation and damage to the mucosa. Tubal damage is secondary to sexually transmitted pelvic infections. The most frequently found microorganisms are: Chlamydia Trachomatis, Neisseria Gonorrhoeae and Mycoplasma Hominis among others. It is estimated that with one episode of acute pelvic disease there will be $30 \%$ infertility, with two $50 \%$ and with three $70 \%$. These predictions are alarming, especially among the young population, in which the risk is greater, especially if there is more than one partner [5]-[15].

One of the most important prognostic factors for human fertility is the age of the woman. It can be said that one third of women who extend pregnancy into their mid to late thirties have fertility problems and at least half of those over forty experience difficulties conceiving. The period of greatest fertility coincides between 20 - 24 years of age to decrease as age increases [1].

Approximately $30 \%$ to $40 \%$ of all infertility is male factor, due to retrograde ejaculation, varicocele, impotence, hormonal deficiencies, sperm count disorders, STIs, drug use, heavy smokers, alcoholism, prescription drugs such as Cimetidine, Spironolactone, and Nitrofurantoin, among others [7].

Due to the trends of the modern world, the incidence of infertility tends to increase. The right to have children is part of family planning programs in all 
countries, which, according to their priorities and capacities, decide to what extent they support medical coverage for treatments [1] [2].

Although the estimates of its incidence are not very precise and vary according to the geographical region, approximately between $8 \%$ and $12 \%$ of couples experience some problem of this type during their fertile life, which, extrapolated to the world population, it represents between 50 and 80 million people. Even more recent publications cite even higher figures and acknowledge a general trend towards an increase in the incidence of infertility, which can reach $20 \%[7]$.

The prevalence of infertility varies from one country to another and between groups within the same country due to living conditions, diet, health care, education, genetic inheritance, and use of medications [5].

In Spain, in recent decades, for example, it has become the country with the lowest birth rate with 1.36 children per family. The United States has a 2.1 fertility rate, Cuba 1.5 children. The participation of women in the world of work, the economic and social situation and the desire for procreation at increasingly advanced ages are the causes that have led her to this serious situation [8]. In Chile, infertility affects approximately $15 \%$ of couples of childbearing age. Similar figures are reported in the United States at 10\% - 15\% and England at 10\% [3].

In Cuba, it is stated that there are an estimated 300,000 couples susceptible to medical attention for infertility. According to data from the Center for Population and Development Studies (CEPDE), the National Office of Statistics and Information (ONEI), Cuba, in 2012 the fertility rate was 1.69; situation that has been occurring for several decades [3] [9].

Scientific and technological advances in the area of human reproduction in general and in the treatment of the infertile couple in particular, in recent times, have been impressive [9]. These advances have caused changes in the way of handling the infertile couple, they have made it practically more efficient, with better success rates, and that the results are evaluated not only from the point of view of success, but from the analysis of the cost-benefit of each procedure [10].

Precisely, among the treatments to be carried out to solve some pathologies that cause infertility, is the surgical treatment through laparoscopic surgery. Laparoscopy (LPS) is a technique that allows the vision of the abdominopelvic cavity through the laparoscope, an instrument that is inserted through a small incision and consists of a light source transmitted by an optical fiber, and a camera that is connected to a television monitor [11]-[20].

Gynecological LPS, from its first applications as a diagnostic technique, has undergone significant development, and is currently applicable in practically all gynecological interventions, framed within the concept of minimally invasive surgery [16] [17] [18].

From monocular vision to robotic surgery, a long period of time has passed. In the $21^{\text {st }}$ century, the development of robotics has allowed the successful use of the Da Vinci robot, a new technology that offers greater precision and comfort 
for the surgeon, offering a three-dimensional view [16] [17] [18] [19] [20].

Laparoscopic surgery has made it possible to perform different treatments on the uterine tubes, release of adhesions, myomectomies, treatment of endometriosis, etc., which contribute to improve or resolve some causes of female infertility [20]-[34].

In the province of Cienfuegos there have always been consultations aimed at the care of the infertile couple, it was not until 2010 that the Territorial Infertility Center was established, whose main objective is assisted reproduction. Taking into account that infertility in the couple has been on the rise and today it has become one of the main problems of Cuban health, there is also a lack of publication of the results obtained, it was planned to carry out this research with the objective of demonstrating the main epidemiological clinical factors, as well as the cause of infertility in female patients who underwent surgical treatment, and thus, to improve the quality of care for the infertile couple.

SCIENTIFIC PROBLEM: What are the characteristics of infertile patients who underwent surgical treatment and their results, who are cared for at the Territorial Center for Assisted Reproduction of Cienfuegos?

PRACTICAL CONTRIBUTION: By characterizing these patients, valuable results will be provided that will improve the quality of both provincial and territorial consultations, satisfying the wishes of the couple who made her attend this consultation one day, with the desire to procreate.

\section{OVERALL OBJECTIVE}

Characterize the patients with the infertility diagnosis who underwent surgical treatment, and their results, treated at the Territorial Center for Assisted Reproduction, in Cienfuegos, from January 2015 to December 2016.

\section{SPECIFIC OBJECTIVES}

1) Relate the causes of infertility (Ovarian, Tubal and Uterine) with clinical epidemiological variables.

2) Evaluate the results of the surgical treatment of the patients under study.

\section{Methodological Design}

Study type: Observational, descriptive, prospective, cross-sectional in a series of cases.

Scenario: Territorial Center for Assisted Reproduction, inserted in the Department of External Consultation of the Dr. Gustavo Aldereguía Lima University General Hospital in Cienfuegos.

Study Period: From January 2015 to December 2016.

Universe: The 186 medical records reviewed and suitable for the study for their information, belonging to patients diagnosed with infertility, who underwent surgical treatment in the period from January 2015 to December 2016.

Inclusion Criteria: All infertile patients, who underwent surgery for minimally invasive or conventional surgery in the period.

For this, clinical-epidemiological variables such as age, skin color, pelvic in- 
flammatory disease, personal pathological history, number of pregnancies, number of deliveries, number of abortions, age of first sexual intercourse, cause of infertility, time attended in consultation, previous pelvic surgery, preoperative diagnosis, type of surgery, type of treatment, and results of the surgery. Techniques and Procedure

Obtaining the information:

For this research, an exhaustive bibliographic review of the subject under study was carried out at the Medical Sciences Informatics Center, through the informed database, the library of the Dr. Gustavo Aldereguía Lima General University Hospital in Cienfuegos, in the Hemeroteca of the Department of Master of the Faculty of Medical Sciences of Cienfuegos, as well as on the Internet.

Collection of information:

The information necessary for the study was obtained from a thorough review of the medical records of women diagnosed with infertility who underwent surgical treatment. Medical records that had incomplete, unreadable or erroneous information were considered unsuitable and were excluded from the study. The review of the medical records was done by the study author with the help of his tutor.

Processing methods, information analysis and techniques to use:

Once all the necessary information for the study was collected, it was taken to a database created for this purpose in the SPSS statistical software in its version 15.0, which also allowed us to apply Descriptive Statistics procedures to obtain the results and his analysis; as well as expressing the results in variable relation tables expressed in number and percent. Because it is a study with only descriptive intent and because the entire universe defined for the research is used, it is not necessary to use the procedures of Inferential Statistics. Microsoft Word was used as a word processor.

As a summary measure, the percentage was used.

The presentation was made using tables.

Discussion and Analysis:

Once the analysis and discussion of the results had been carried out, these were compared with those of other authors through an inductive-deductive method, which enabled the proposed objectives to be achieved and the conclusions and recommendations to be issued.

\section{Analysis and Discussion of Results}

It can be verified that the most frequent age group was 26 to 30 years with 65 patients undergoing surgical treatment, representing 34.9\%, followed by the group from 31 to 35 years with 59 females for $31.7 \%$. The predominant cause was tubal with 121 patients for $65.05 \%$, followed by ovarian cause with 59 women, for $31.7 \%$. The tubal cause was the most predominant, with the age group of 26 to 30 years being the most affected, with 40 females for $33.1 \%$. The uterine cause was the least representative with 6 patients for $3.2 \%$, with the least affected 
group being women over 40 years of age.

Infertility is a problem that humanity has faced since time immemorial and that has important connotations, especially in the psychic and social order of human beings. For most people, having children is an extremely important element, due to the multiple social and cultural meanings that this implies [32] [33] [34].

In previous research by Fernández Borbón [11], it was found that $59.4 \%$ of women who were part of an infertile couple were below 30 years of age, similar results were obtained by León Díaz [3] and Urdaneta [12]; results that coincide with the present study.

It is proposed that the causal factors of infertility vary according to the country, the year and the population studied, and it is then known that ovulatory and endocrine factors predominate in developed countries, while in the developing countries the tube-peritoneal factor predominates [3] [12].

According to an article published by the American Society for Reproductive Medicine [31] factors related to the tubes, as well as those that affect the peritoneum (the lining of the pelvis and abdomen) cause about 35\% of all infertility problems.

In a study by Garrido Casado [29], it was found that $30 \%-40 \%$ of women with difficulties conceiving have infertility problems caused by an alteration in the fallopian tubes, results that differ with this study.

According to a study carried out by Lin [28], it was found that women over 40 years old had infertility of tubal origin, results that differ with this work.

I consider that the early start of sexual relations in adolescence and other risk factors such as frequent change of partners, sexually transmitted infections (STIs), repetitive episodes of pelvic inflammatory disease, voluntary interruptions of gestation, among others, may have a direct relationship that there is a predominance of tubal factor as the most frequent cause of infertility in this age group.

With regard to the color of the skin, it was obtained that 134 patients are white representing $72 \%$ followed by 28 mestizo females for $13 \%$ and finally 24 black women for $13 \%$. The tubal cause was the most predominant, with the white color being the most affected, with 89 females for $73.5 \%$.

Llaguno Concha [29] in his study obtained similar results as in this investigation, with a predominance of the white race, so it is expressed that these results were due to the fact that the population of the territory according to the Population Census and Registry corresponds to the people of white skin color.

Regarding the personal pathological history of the patients, it was found that 111 patients do not report any type of disease for $59.7 \%$; of which 76 represent $62.8 \%$ of tubal causes, followed by 41 females who suffer from other previously described pathologies, representing $22 \%$.

It is considered that not all the disorders present in a couple have clinical significance nor will they determine the subsequent behavior of the doctor to the same extent. In practice, it is especially interesting to detect causal factors clearly 
associated with the decrease in the probability of pregnancy and that are treatable through the available procedures.

In Table 1, it is described that the previous pelvic inflammatory disease predominated in 152 patients, representing 81.7\%, the tubal cause being the most frequent in 116 women for $95.9 \%$, and previous pelvic surgery was present in 99 women for $53.2 \%$.

The pathologies that can alter the Tuboperitoneal factor are numerous and, despite the fact that infectious diseases are often considered the most frequent, there are studies that indicate that the most important factor is the history of pelvic surgery, especially myomectomies and oophorectomies, because the most frequent cause of tubal problems is infections [33].

Infectious processes are a frequent cause of damage to the oviduct. These infections are usually genitally elevated and may be sexually transmitted or pathogenic microorganisms from the vaginal flora. Inflammation of the fallopian tubes and/or other pelvic organs is known as pelvic inflammatory disease (PID) and is a common cause of tubal injury, especially of its distal portion. The infertility rate after an episode of PID is reported to be $12 \%$; after 2 episodes, 35\%; and then $3,75 \%$. In general, PIDs are responsible for $32 \%$ of the causes of adhesions capable of producing infertility, and pelvic operations are another risk factor for the formation of adhesions in 75\% of women [33].

I believe that professionals must justify any procedure and carry out all general measures to avoid scarring and adhesions that result in infertility problems, it is also recommended to guide women on the knowledge of these risk factors associated with female infertility.

When analyzing the obstetric history of the patients, it was found that 71 had never been pregnant, for $38.2 \%$, (nulligrams), and of them, 37 its cause was a tubal factor, for $30.6 \%$; followed by 50 women who had the antecedent of 2 previous pregnancies, for $26.9 \%$, and of these, had associated tubal cause $25.6 \%$.

Table 1. Relation of the causes of pelvic infertility with inflammatory disease and previous surgery. Territorial Center for Assisted Reproduction, Cienfuegos. January 2015 to December 2016.

\begin{tabular}{|c|c|c|c|c|c|c|c|c|}
\hline & \multicolumn{6}{|c|}{ Cause of Infertility } & \multirow{2}{*}{\multicolumn{2}{|c|}{ Total }} \\
\hline & \multicolumn{2}{|c|}{ Ovarian } & \multicolumn{2}{|c|}{ Tubal } & \multicolumn{2}{|c|}{ Uterine } & & \\
\hline & No & $\%$ & No & $\%$ & No. & $\%$ & No. & $\%$ \\
\hline \multicolumn{9}{|c|}{ Previous Pelvic Inflammatory Disease } \\
\hline YES & 32 & 54.2 & 116 & 95.9 & 4 & 66.7 & 152 & 81.7 \\
\hline NO & 27 & 45.8 & 5 & 4.1 & 2 & 33.3 & 34 & 18.3 \\
\hline \multicolumn{9}{|c|}{ Previous Pelvic Surgery } \\
\hline YES & 25 & 42.4 & 70 & 57.9 & 4 & 66.7 & 99 & 53.2 \\
\hline NO & 34 & 57.6 & 51 & 42.1 & 2 & 33.3 & 87 & 46.8 \\
\hline
\end{tabular}

Source: clinical history. 
Regarding the number of deliveries, it was found that 151 patients had not presented any previous delivery for $81.2 \%$; of these, 97 of tubal cause for $80.2 \%$ followed the group that only had a previous delivery with 29 patients for $15.6 \%$.

It was also found that 84 patients had had pregnancy loss for $45.2 \%$, followed by 64 women who had some type of abortion applied for $34.4 \%$. Generalizing, it was observed that the tubal factor was the prevailing one according to the form of pregnancy loss.

In a study carried out by León Díaz [3], secondary infertility predominated, motivated by a higher frequency of abortions and ectopic pregnancies than in previous pregnancies, coinciding with this research, but at the same time, it differs with the tubal factor.

In studies carried out by Fernández Borbón [11] and Urgellés [22] secondary infertility predominated with a predominance of the tube-peritoneal factor coinciding with the present investigation and differing from Urdaneta [12] where primary infertility predominated with $63.3 \%$ of the patients differing from the results of this study.

I consider that the investigation process of the infertile couple goes from the simple to the complex, in a consistent and staggered way, always according to the possibilities of the level of care, which will lead to the solution of the problem.

Table 2 shows that 143 patients began their first sexual relationship between 15 to 20 years of age, for $76.9 \%$ of whom 93 were tubal and, in relation to the time attending the consultation, the period from 1 to 5 predominated years for $58.6 \%$.

Adolescence is a well-defined stage of human life, the World Health

Table 2. Relation of the causes of infertility with the beginning of the first sexual relations and time attending the consultation. Territorial Center for Assisted Reproduction, Cienfuegos. January 2015 to December 2016.

\begin{tabular}{|c|c|c|c|c|c|c|c|c|}
\hline & \multicolumn{6}{|c|}{ Infertility causes } & \multirow{2}{*}{\multicolumn{2}{|c|}{ Total }} \\
\hline & \multicolumn{2}{|c|}{ Ovarian } & \multicolumn{2}{|c|}{ Tubaric } & \multicolumn{2}{|c|}{ Uterine } & & \\
\hline & No. & $\%$ & No. & $\%$ & No. & $\%$ & No. & $\%$ \\
\hline \multicolumn{9}{|l|}{ First sexual relationships } \\
\hline Less than 15 years & 13 & 22 & 27 & 22.3 & 2 & 33.4 & 42 & 22.6 \\
\hline From 15 to 20 years & 46 & 78 & 93 & 76.9 & 4 & 66.6 & 143 & 76.9 \\
\hline from 21 to 25 years & - & - & 1 & 0.8 & - & - & 1 & 0.5 \\
\hline \multicolumn{9}{|c|}{ Time going to consultation } \\
\hline Less than 1 year & 20 & 33.9 & 26 & 21.5 & 1 & 16.7 & 47 & 25.3 \\
\hline from 1 to 5 years & 29 & 49.1 & 76 & 62.8 & 4 & 66.6 & 109 & 58.6 \\
\hline from 6 to 10 years & 9 & 15.2 & 13 & 10.7 & 1 & 16.7 & 23 & 12.3 \\
\hline More than 10 years & 1 & 1.8 & 6 & 5 & - & - & 7 & 3.8 \\
\hline Total & 59 & 100 & 121 & 100 & 6 & 100 & 186 & 100 \\
\hline
\end{tabular}

Source: clinical history. 
Organization (WHO) defines it as stage that takes place during the second decade of human life, that is, between 10 and 19 years old, there being a difference between their early stage 10 to 14 years old and the late stage between 15 to 19 years old [34]. What I consider among the challenges that adolescents must face are those related to the practice of their sexuality and the risk that this entails for their reproductive health, due to the possible advent of unwanted pregnancies, their consequences, as well as the risk of acquiring a Sexually Transmitted Infection.

In Table 3 it was reported that according to the preoperative diagnosis, hydrosalpinx was the most frequent with 83 patients for $44.6 \%$, followed by polycystic ovarian disease with 34 females for $18.3 \%$, with the most representative tubal cause for $65.3 \%$.

The type of surgery with minimal access and conventional was considered depending on each one of the preoperative diagnoses of infertile patients, confirming that 169 patients were treated surgically for minimum access, representing $90.9 \%$; of the 112 of tubal cause for $92.6 \%$, only 17 women underwent conventional

Table 3. Relation of the causes of infertility with diagnosis, treatment and results of surgery. Territorial Center for Assisted Reproduction, Cienfuegos. January 2015 to December 2016.

\begin{tabular}{|c|c|c|c|c|c|c|c|c|}
\hline & \multicolumn{6}{|c|}{ Infertility causes } & \multirow{2}{*}{\multicolumn{2}{|c|}{ Total }} \\
\hline & \multicolumn{2}{|c|}{ Ovarian } & \multicolumn{2}{|c|}{ Tubal } & \multicolumn{2}{|c|}{ Uterine } & & \\
\hline & No. & $\%$ & No & $\%$ & No. & $\%$ & No & $\%$ \\
\hline \multicolumn{9}{|l|}{ Presurgical Diagnosis } \\
\hline Hidrosalpinx & 4 & 6.8 & 79 & 65.3 & - & - & 83 & 44.6 \\
\hline Poliquistosis Ovárica & 32 & 54.2 & 2 & 1.7 & - & - & 34 & 18.3 \\
\hline Obstrucción Tubárica & - & - & 31 & 25.6 & - & - & 31 & 16.7 \\
\hline Endometriosis & 8 & 13.6 & - & - & 2 & 33.3 & 10 & 5.4 \\
\hline Mioma Uterino & 1 & 1.7 & - & - & 4 & 66.7 & 5 & 2.7 \\
\hline Otras & 14 & 23.7 & 9 & 7.4 & - & - & 23 & 12.4 \\
\hline \multicolumn{9}{|l|}{ Type of surgery } \\
\hline Minimum Access & 55 & 93.2 & 112 & 92.6 & 2 & 33.3 & 169 & 90.9 \\
\hline Conventional & 4 & 6.8 & 9 & 7.4 & 4 & 66.7 & 17 & 9.1 \\
\hline \multicolumn{9}{|l|}{ Type of treatment } \\
\hline Tubal plasty & 2 & 3.4 & 58 & 47.9 & - & - & 60 & 32.3 \\
\hline Salpingectomy & 4 & 6.8 & 50 & 41.3 & 1 & 16.7 & 55 & 29.6 \\
\hline Cribriform perforation of the ovary & 33 & 55.9 & 4 & 3.3 & - & - & 37 & 19.9 \\
\hline Endometrioma Exceresis & 8 & 13.6 & - & - & - & - & 8 & 4.3 \\
\hline Myomectomy & 2 & 3.4 & - & - & 4 & 66.6 & 6 & 3.2 \\
\hline Others & 10 & 16.9 & 9 & 7.4 & 1 & 16.7 & 20 & 10.8 \\
\hline
\end{tabular}

Source: clinical history. 
surgery for $9.1 \%$.

Among surgical treatments, tubal plasty predominated with 60 patients for $32.3 \%$, followed by salpingectomy with 55 females for $29.6 \%$, and thirdly there is cribriform perforation of the ovary with 37 patients for $19.9 \%$, of which $33 \mathrm{fe}$ males constituted the ovarian factor.

In an article published by León Díaz [3], it was found that among the patients undergoing some type of treatment, pharmacological treatment predominated and, among the surgical treatments carried out, tubal factor predominated as the cause of infertility. The results coincide with our work.

Research carried out by Jin [32], and Słabuszewska-Jóźwiak [33], showed that the laparoscopic technique is an effective therapeutic method to treat endometretriosis-related sterility, results that are consistent with the research.

I consider that the success of the surgical procedure will depend on the relevant physical findings, the review of the medical history, the laboratory and complementary tests that support the diagnosis. Furthermore, it is important to explain to the patient and family the context of the disease, the benefit of different surgical interventions, additional diagnostic tests and possible non-surgical alternatives when this is appropriate, as well as what would happen if no intervention were performed. In this process, communication between the professional and the consultants is essential to define realistic objectives to optimize and facilitate surgical treatment.

When evaluating the results of the surgical treatment, in relation to the causes of infertility, which led to it, it was found that 183 patients responded satisfactorily to the surgical treatment for $98.4 \%$, only $1.6 \%$ responded unsatisfactorily to it where it could not be fulfilled the objective of the surgery since one had to change from one to the other or because a complication occurred during the operation.

No published evidence was found with whom to compare according to the results of the surgical treatment.

It was considered that the results obtained depending on the preoperative evaluation, the expected surgical technique and the postoperative destination of the patient (outpatient follow-up or hospitalization, hospital ward or intensive care); which allowed identifying, in the patients, possible risk factors for postoperative morbidity and mortality.

\section{KEY FINDINGS}

- The predominant age group was 26 to 30 years, with the tubal cause being the representative factor.

- No personal pathological history was reported in most of the patients.

- In the majority, previous pelvic inflammation and pelvic surgery predominated.

- Most of the females had no previous pregnancies.

- Most started their first sexual relations between 15 to 20 years of age.

- The most frequent preoperative diagnosis was hydrosalpinx, with the least 
accessible surgery being the predominant one.

- The results of the surgical treatment were satisfactory.

\section{Conclusions}

It was concluded that the majority of infertile women were between 26 and 30 years of age, the first sexual relations were more common in adolescence. The most frequent cause of infertility was the tubal factor, with secondary infertility being the prevalent one; minimal access surgery predominated, surgical treatment for hydrosalpinx as a clinical diagnosis. Minimal access surgery is a variant of effective importance and a good alternative, especially in patients who seek a solution to their reproductive problem in order to fulfill their life purpose, so that medical treatment and assisted reproductive techniques are interrelated. complex manner, showing the need for multidisciplinary management, which depend on the severity of the disease, and the woman's desire to conceive. Therefore, nothing can replace a well-planned and well-developed operation when the best possible surgical results are desired.

\section{RECOMMENDATIONS}

- Raise professional development to develop the necessary technical skills, guaranteeing better care not only for infertile patients, but also for patients who are of reproductive age, and intervening in those risk factors that can be modified and thus prevent these patients from at a certain time they behave as infertile.

- Guarantee that the professionals offer quality assistance from the operating room to improve the results of the surgery and the level of satisfaction of the patients, contributing with the support of the territorial program of assisted reproduction.

\section{Conflicts of Interest}

The authors declare no conflicts of interest regarding the publication of this paper.

\section{References}

[1] Pagés, G., Aller, J. and Álvarez, J. (2006) Historia y Epidemiología. In: Pagés, G. and Aller, J., Eds., Fertilab. Human Reproduction Unit, AMOLCA, Caracas, 143-162. http://www.fertilab.net/ginecopedia/fertilidad/

[2] Balasch, J. (2012) Diagnosis of Sterility and Infertility. Elsevier, Barcelona. http://www.elsevier.es/en/node/2035537

[3] León Díaz, L., Reyes Pérez, A.M., Rojas Quintana, P., Reyes Pérez, A.M. and Chávez González, N.M. (2016) Characterization of the Pregnant Patient Attended at the Assisted Reproduction Center. Medisur, 14, 300-306. http://scielo.sld.cu/scielo.php?script=sci abstract\&pid=S1727-897X2016000300012

[4] Rodríguez-Purata, J., Cervantes, E., Luna, M. and Sandler, B. (2016) What Is the True Role of Surgery in Infertility Associated with Endometriosis. Ginecología $y$ Obstetricia de México, 84, 37-45.

http://www.medigraphic.com/pdfs/ginobsmex/gom-2016/gom161g.pdf 
[5] Fábregues Gasol, F. (2014) Sterility and Infertility. In: González-Merlo, J., González Bosquet, E. and González Bosquet, J., Eds., Ginecología, 9th Edition, Elsevier Publishing House, Madrid, 119-130.

[6] Hernández Durán, D. and Díaz Mitjans, O. (2010) Pelvic Inflammatory Disease. Revista Cubana de Obstetricia y Ginecología, 36, 613-631.

[7] Rojas, P., Torres, L. and Medina, D. (2011) Infertility. Revista Medisur 9, 340-350. http://www.medisur.sld.cu/index.php/medisur/issue/view/54

[8] Register, R.S. (1996) Epidemiology of Infertility in Cuba. Cuban Journal of Obstetrics and Gynecology, 6, 80-84.

[9] Vega Hernández, M. and Vega Hernández, M. (2014) Fertility Trend in Cuba: Its Main Causes and Consequences. Cuban Rev Public Health, 40, 187-197. https://pesquisa.bvsalud.org/portal/resource/pt/lil-709205

[10] Celis, L.A. (2012) Infertility Symposium, Current Topics. Revista Peruana de Ginecología y Obstetricia, 58, 77-78. http://www.redalyc.org/articulo.oa?id=323428204002

[11] Fernández Borbón, H., Valle Rivera, T., Fernández Ramos, I. and Ramírez Pérez, N. (2013) Characterization of Infertility in the Pinar del Río Municipality. Revista de Ciencias Médicas de Pinar del Río, 17, 64-73.

http://scielo.sld.cu/scielo.php?script=sci arttext\&pid=S0864-212520080004 $\underline{00003 a}$

[12] Urdaneta, J., Cantillo, E., Alarcón, A., Karame, A., Salazar de Acosta, J., Romero, Z., et al. (2013) Tubal Infertility and Genital Infection by Chlamydia trachomatis, Ureaplasma, urealyticum. Revista Chilena de Obstetricia y Ginecologia, 78, 32-43. https://doi.org/10.4067/S0717-75262013000100006

[13] Agarwal, A. and Majzoub, A. (2017) Role of Antioxidants in Assisted Reproductive Techniques. The World Journal of Men's Health, 35, 77-93. https://wjmh.org/Synapse/Data/PDFData/2074WJMH/wjmh-35-e3.pdf

[14] Agarwal, A., Virk, G., Ong, C. and du Plessis, S.S. (2014) Effect of Oxidative Stress on Male Reproduction. The World Journal of Men's Health, 32, 1-17. https://doi.org/10.5534/wjmh.2014.32.1.1

[15] Hoffman, B.L., Schorge, J.O., Schaffer, J.I., Halvorson, L.M., Bradshaw, K.D. and Cunningham, F.G. (2014) Assessment of the Infertile Couple. In: Williams Gynecology, 2nd Edition, McGraw Hill Interamericana, Mexico, 506-528.

[16] Cabezas Cruz, E. (2006) Manual of Procedures in Gynecology. Ciencias Médicas, Havana, 57-66.

[17] Rizk, B., Turki, R., Lotfy, H., Ranganathan, S., Zahed, H., Freeman, A.R., Shilbayeh, Z., Sassy, M., Shalaby, M. and Malik, R. (2015) Surgery for Endometriosis-Associated Infertility: Do We Exaggerate the Magnitude of Effect? Facts, Views \& Vision in ObGyn, 7, 109-118.

[18] González-Merlo, J., González Bosquet, E. and González Bosquet, J. (2014) Assisted Reproduction Techniques. In: Gynecology, 9th Edition, Elsevier Publishing House, Madrid, 131-143.

[19] Deroux, A., Dumestre-Perard, C., Dunand-Faure, C., Bouillet, L. and Hoffmann, P. (2016) Female Infertility and Serum Auto-Antibodies: A Systematic Review. Clinical Reviews in Allergy \& Immunology, 53, 78-86. https://doi.org/10.1007/s12016-016-8586-Z

[20] Aubuchon, M., Burney, R.O., Schust, D.J. and Yao, M.W.M. (2013) Sterility and Assisted Reproduction Techniques. In: Berek, J.S. and Berek, D.L., Eds., Berek and Novak Gynecology, 15th Edition, Elsevier Publishing House, Madrid, 1133-1189. 
[21] Manrique Fuentes, M. (2011) Classes of Residents, Laparoscopy. Technique, Indications and More Novel Aspects. Pomegranate.

[22] Al Subhi, T., Al Jashnmi, R.N., Al Khaduri, M. and Gowri, V. (2013) Prevalence of Tubal Obstruction in the Hysterosalpingogram of Women with Primary and Secondary Infertility. Journal of Reproduction \& Infertility, 14, 214-216. https://www.ncbi.nlm.nih.gov/pmc/articles/PMC3911818/

[23] Hoffman, B.L., Schorge, J.O., Schaffer, J.I., Halvorson, L.M., Bradshaw, K.D. and Cunningham, F.G. (2014) Treatment of the Infertile Couple. In: Williams Gynecology, 2nd Edition, Editorial McGraw Hill Interamericana, Mexico, 529-553.

[24] Shah, P.R. and Adlakha, A. (2014) Laparoscopic Management of Moderate: Severe Endometriosis. Journal of Minimal Access Surgery, 10, 27-33. https://doi.org/10.4103/0972-9941.124463

[25] Aydin, T., Yucel, B., Aksoy, H. and Ekemen, S. (2016) Successful Laparoscopic Management of a Rare Complication after Embryo Transfer: Ovarian Pregnancy. A Case Report and Up-to-Date Literature Review. Wideochirurgia I Inne Techniki Maloinwazyjne, 10, 574-579. https://pubmed.ncbi.nlm.nih.gov/26865895/

[26] Ashrafi, M., Fakheri, T., Kiani, K., Sadeghi, M. and Akhoond, M.R. (2014) Impact of the Endometrioma on Ovarian Response and Pregnancy Rate in in Vitro Fertilization Cycles. International Journal of Fertility and Sterility, 8, 29-34.

[27] González-Comadran, M., Schwarze, J.E., Zegers-Hochschild, F., Souza, M.D., Carreras, R. and Checa, M.Á. (2017) The Impact of Endometriosis on the Outcome of Assisted Reproductive Technology. Reproductive Biology and Endocrinology, 15, 8.

[28] Lin, M.H., Hwu, Y.M., Lin, S.Y. and Lee, R.K. (2013) Treatment of Infertile Women with Unilateral Tubal Occlusion by Intrauterine Insemination and Ovarian Stimulation. Taiwanese Journal of Obstetrics and Gynecology, 52, 360-364. https://pubmed.ncbi.nlm.nih.gov/24075374/

[29] Llaguno Concha, A.Á. (2015) Socio-Epidemiological and Clinical Factors Present in Women Seen in Infertility Consultation. Revista Cubana de Obstetricia y Ginecología, 41, pages.

http://scielo.sld.cu/scielo.php?script=sci arttext\&pid=S0138-600X2015000400006\&1 $\underline{\mathrm{ng}}=\mathrm{es} \& \mathrm{nrm}=\mathrm{iso}$

[30] Neumayer, L. and Vargo, D. (2013) Principles of Preoperative and Operative Surgery. In: Townsend, C.M., Beauchamp, R.D., Evers, B.M. and Mattox, K.L., Eds., Sabiston Treatise on Surgery Biological Foundations of Modern Surgical Practice, 19th Edition, Elsevier, Amsterdam, 210-239.

https://doi.org/10.1016/B978-1-4377-1560-6.00011-1

[31] Aller, J., Aller, B. and Pagés, G. (2006) Tube-Peritoneal Factor. In: Pagés, G. and Aller, J., Eds., FERTILAB. Human Reproduction Unit Caracas, AMOLCA, Caracas, 293-312. http://www.fertilab.net/directorios/medicos fertilab/

[32] Jin, X. and Ruiz Beguerie, J. (2014) Laparoscopic Surgery for Subfertility Related to Endometriosis: A Meta-Analysis. Taiwanese Journal of Obstetrics \& Gynecology, 53, 303-308. https://doi.org/10.1016/j.tjog.2013.02.004

[33] Słabuszewska-Jóźwiak, A., Ciebiera, M., Baran, A. and Jakiel, G. (2015) Effectiveness of Laparoscopic Surgeries in Treating Infertility Related to Endometriosis. Annals of Agricultural and Environmental Medicine, 22, 329-331. https://doi.org/10.5604/12321966.1152089

[34] Díaz Bernal, Z. and GarcíaJordá, D. (2011) The Gender Perspective and the Doctor-Patient Relationship for the Problem of Infertility. Revista Cubana de Salud Pública, 40, 136-143. https://www.researchgate.net/publication/264052522 